\title{
The impacts of artificial reefs on the income of artisanal fishers in Terengganu, Malaysia
}

\begin{abstract}
The marine fishery resources in Malaysia have declined considerably over the past decades primarily due to overfishing and overcapacity. In response, the government has deployed artificial reefs (ARs) to conserve and enhance the natural fish stocks in marine waters. Specifically, AR deployment was expected to rehabilitate the degraded fish stocks and secure the livelihoods of the fishers along the coastal villages. This study examined the impact of ARs on fisher households' income in Terengganu, Malaysia. The data for this study was obtained from a survey involving 312 fisher respondents in 3 contiguous districts, namely, Besut, Setiu, and Kuala Terengganu. The results showed a difference in the value of catch of fishers fishing in an AR and those fishing in non-AR area. Fishers fishing near AR areas were found to benefit from higher monthly catch value. The regression models indicated that fishing in an AR area helps reduce the vessel operating costs. The catch value also significantly differed between fishers using an inboard-powered vessel and those fishers using outboard-powered vessels (on an average obtained MYR 5935 per month and MYR 3126 per month, respectively). Fishers using inboard-powered vessels were also less dependent on ARs as they were able to fish further to the sea.
\end{abstract}

Keyword: Artificial reefs; Terengganu; Fisher's income; AR deployment; Malaysian fisheries 